\title{
Effect of therapeutic hypothermia against renal injury in a rat model of asphyxial cardiac arrest: A focus on the survival rate, pathophysiology and antioxidant enzymes
}

\author{
SO EUN KIM ${ }^{1 *}$, HA-YOUNG SHIN ${ }^{2 *}$, EUI-YONG LEE ${ }^{2}$, YEO-JIN YOO², RYUN-HEE KIM ${ }^{2}$, \\ JEONG-HWI CHO ${ }^{2}$, TAE-KYEONG LEE ${ }^{3}$, DONGCHOON AHN ${ }^{2}$, BYUNG-YONG PARK ${ }^{2}$, \\ JAE CHOL YOON $^{1}$, SEONGKWEON HONG ${ }^{4}$, IN-SHIK KIM ${ }^{2}$, HYUN-JIN TAE ${ }^{2}$ and MOO-HO WON ${ }^{5}$

\begin{abstract}
${ }^{1}$ Department of Emergency Medicine, Research Institute of Clinical Medicine of Jeonbuk National University, Jeonju, Jeollabuk-do 54907; ${ }^{2}$ College of Veterinary Medicine and Biosafety Research Institute, Jeonbuk National University, Iksan, Jeollabuk-do 54596; ${ }^{3}$ Department of Biomedical Science and Research Institute for Bioscience and Biotechnology, Hallym University, Chuncheon, Gangwon-do 24252; ${ }^{4}$ Department of Surgery, Kangwon National University Hospital, School of Medicine, Kangwon National University, Chuncheon, Gangwon-do 24289; ${ }^{5}$ Department of Neurobiology, School of Medicine, Kangwon National University, Chuncheon, Gangwon-do 24341, Republic of Korea
\end{abstract}

Received September 3, 2021; Accepted October 27, 2021

DOI: $10.3892 / \mathrm{mmr} .2021 .12535$

\begin{abstract}
Although multi-organ dysfunction is associated with the survival rate following cardiac arrest (CA), the majority of studies to date have focused on hearts and brains, and few studies have considered renal failure. The objective of the present study, therefore, was to examine the effects of therapeutic hypothermia on the survival rate, pathophysiology and antioxidant enzymes in rat kidneys following asphyxial CA. Rats were sacrificed one day following CA. The survival rate, which was estimated using Kaplan-Meier analysis, was $42.9 \%$ one day following CA. However, hypothermia, which was induced following $\mathrm{CA}$, significantly increased the survival rate $(71.4 \%)$. In normothermia rats with $\mathrm{CA}$, the serum blood urea nitrogen level was significantly increased one day post-CA. In addition, the serum creatinine level was significantly increased one day post-CA. However, in CA rats exposed to hypothermia, the levels of urea nitrogen and creati-
\end{abstract}

Correspondence to: Professor Hyun-Jin Tae, College of Veterinary Medicine and Biosafety Research Institute, Jeonbuk National University, 79 Gobong-ro, Iksan, Jeollabuk-do 54596, Republic of Korea

E-mail: hjtae@jbnu.ac.kr

Professor Moo-Ho Won, Department of Neurobiology, School of Medicine, Kangwon National University, 1 Kangwondaehak-gil, Chuncheon, Gangwon-do 24341, Republic of Korea

E-mail: mhwon@kangwon.ac.kr

*Contributed equally

Key words: asphyxial cardiac arrest, post-cardiac arrest syndrome, hypothermia treatment, kidney, histopathology, antioxidant enzymes nine significantly decreased following CA. Histochemical staining revealed a significant temporal increase in renal injury after the normothermia group was subjected to CA. However, renal injury was significantly decreased in the hypothermia group. Immunohistochemical analysis of the kidney revealed a significant decrease in antioxidant enzymes (copper-zinc superoxide dismutase, manganese superoxide dismutase, glutathione peroxidase and catalase) with time in the normothermia group. However, in the hypothermia group, these enzymes were significantly elevated following CA. Collectively, the results revealed that renal dysfunction following asphyxial CA was strongly associated with the early survival rate and therapeutic hypothermia reduced renal injury via effective antioxidant mechanisms.

\section{Introduction}

Cardiac arrest (CA), also known as cardiopulmonary arrest or circulatory arrest, involves a sudden cessation of normal blood circulation due to the failure of the heart to pump blood adequately (1). CA induces whole-body ischemia, which causes damage to multiple organs, including the brain, heart, kidneys and liver. The majority of research studies involving CA over the past half-century have focused on improving the rate of successful return of spontaneous circulation (ROSC), with significant progress (2-4). Although immediate resuscitation may improve ROSC, the survival rate with a poor prognosis is a concern (5-7). Post-cardiac arrest syndrome (PCAS) refers to the pathophysiological consequences of ROSC following successful cardiopulmonary resuscitation (CPR) following CA (8). PCAS is the main cause of decreased survival following ROSC (9). The early-period PCAS survival rate in patients is only $30 \%$ (5). There is no doubt that the heart and brain are important organs in PCAS. Meanwhile, studies have rarely investigated renal failure following 
CA $(1,10,11)$. Transient impaired renal function is common in patients surviving CA (12). The incidence and impact of kidney dysfunction following CA are not well described (13). In addition, our previous study suggested that the low early survival rate following ROSC in experimental studies (14) may be strongly related to renal failure such as acute kidney injury. One of the most common causes of acute kidney injury is CA (15). Acute kidney injury is a common PCAS developing in $\sim 30 \%$ of in-hospital patients with CA (16).

Reactive oxygen species (ROS) are composed of a series of oxygen intermediates, including the free radical superoxide anion $\left(\mathrm{O}_{2}{ }^{\circ}\right)$, the nonradical hydrogen peroxide $\left(\mathrm{H}_{2} \mathrm{O}_{2}\right)$, the highly reactive hydroxyl free radical $(\mathrm{OH} \bullet)$, peroxynitrite $\left(\mathrm{ONOO}^{-}\right)$and singlet oxygen $\left({ }^{1} \mathrm{O}_{2}\right)(17)$. ROS have been revealed to play an essential role in several experimental renal conditions, such as acute ischemic renal failure, renal graft rejection, acute glomerulonephritis and toxic renal diseases (18). There is significant evidence supporting the synthesis of ROS immediately following acute ischemic stroke (19) and acute myocardial infarction (20). ROS are known to be important in ischemic diseases, such as stroke and myocardial infarction. For example, Hackenhaar et al (21) reported that ROS are generated in the blood of patients with PCAS; however, studies have rarely investigated ROS formation in the kidney following CA during the early post-PCAS period $(22,23)$.

For this reason, it was hypothesized that ROS are important in kidney injury following $\mathrm{CA}$ and contribute to the low survival rate in the early stages of PCAS. To examine this hypothesis, asphyxial CA was induced in rats and the survival rate during the early stages of PCAS was observed. Additionally, immediate and delayed hypothermia were performed to increase the low survival rate associated with PCAS following ROSC. Furthermore, the renal dysfunction was analyzed histopathologically and the changes induced by ROS, such as copper-zinc superoxide dismutase (SOD-1), manganese superoxide dismutase (SOD-2), catalase (CAT) and glutathione peroxidase (GPX) were assessed via immunohistochemical analysis following ROSC.

\section{Materials and methods}

Experimental animals and groups. A total of 62 male Sprague-Dawley (SD) rats (weight, 270-300 g; age, 10 weeks) were obtained from the Experimental Animal Center of Jeonbuk National University (Iksan, Republic of Korea). They were housed at a temperature of $23 \pm 2^{\circ} \mathrm{C}$ and humidity of $60 \pm 10 \%$ under a 12 -h light/dark cycle. They were supplied with free access to food and water. All experimental protocols were approved based on ethical procedures and scientific care by the Institutional Animal Care and Use Committee of Jeonbuk National University (approval no. JBNU 2020-084).

Experimental animals were stratified in three categories [a sham operation group, CA under normothermia, and CA and hypothermia treatment (HT)] as follows: i) group I, a sham group $(n=5)$ was maintained under normothermia conditions without CA; ii) group II, a normothermia group without hypothermia $\left(33^{\circ} \mathrm{C}\right)$ treatment following $\mathrm{CA}(\mathrm{n}=17)$; and iii) group III $(n=40)$, a group that underwent $C A$ under normothermia and were treated with HT after CA for $2 \mathrm{~h}(\mathrm{n}=17), 4 \mathrm{~h}$ $(\mathrm{n}=13)$ and $6 \mathrm{~h}(\mathrm{n}=10)$ following ROSC, where all rats were reheated to normothermia.

$C A$ induction and CPR. CA and CPR were performed as previously described $(24,25)$ with minor modifications (Fig. 1). Briefly, the rats were anesthetized with 2-3\% isoflurane and mechanically ventilated to maintain respiration using a rodent ventilator (Harvard Apparatus). To monitor peripheral oxygen saturation $\left(\mathrm{SpO}_{2}\right)$, a pulse oximetry oxygen saturation probe (Nonin Medical, Inc.) was attached to the left foot. Body temperature was maintained at $37 \pm 0.5^{\circ} \mathrm{C}$ during and following the CA surgery. To monitor electrocardiogram (ECG) changes, electrocardiographic probes (Cytiva) were placed on the limbs to provide three-lead data, and which were monitored continuously. The left femoral artery and right femoral vein were separately cannulated to monitor the mean arterial pressure (MAP) (MLT 1050/D; ADInstruments, Ltd.) and intravenous injection.

Following a 5-min stabilization period, vecuronium bromide $(2 \mathrm{mg} / \mathrm{kg}$; Gensia Sicor Pharmaceuticals, Inc.) was intravenously administered, anesthesia was stopped and mechanical ventilation was withdrawn. A MAP below $25 \mathrm{~mm}-\mathrm{Hg}$ and subsequent pulseless electric activity were used to define CA $(25,26)$. CA was confirmed at 3-4 min following vecuronium bromide injection. At 5 min following CA, CPR was initiated by intravenously administering a bolus injection of epinephrine $(0.005 \mathrm{mg} / \mathrm{kg}$; Sigma-Aldrich; Merck KGaA) and sodium bicarbonate $(1 \mathrm{mEq} / \mathrm{kg}$; Sigma-Aldrich; Merck KGaA) followed by mechanical ventilation with $100 \%$ oxygen and manual chest compressions at a rate of 300/min until MAP reached $60 \mathrm{~mm}-\mathrm{Hg}$ and electrocardiographic activity was observed. Once the animal was hemodynamically stable and spontaneously breathing (usually at $1 \mathrm{~h}$ following ROSC), the catheters were removed and the animal was extubated.

Temperature management among the groups. The body temperature of the normothermia group was maintained at $37 \pm 0.5^{\circ} \mathrm{C}$ during and following the CA surgery and maintained until the rats were sacrificed according to the time schedule. In the hypothermia group, CA was established at normal temperature; then, the body temperature was maintained with ice packs and fans at $33 \pm 0.5^{\circ} \mathrm{C}$ immediately following CPR for 2,4 and $6 \mathrm{~h}$, and they were rewarmed rapidly with the heating pad until the desired temperature $\left(37 \pm 0.5^{\circ} \mathrm{C}\right)$ was achieved. The rats were then returned to their cages until they were sacrificed one day following CPR/ROSC. The body temperature was monitored using a rectal temperature sensor (27).

Serum biochemical analysis. An intraperitoneal injection of $30 \mathrm{mg} / \mathrm{kg}$ pentobarbital sodium (JW Pharm Co., Ltd.) was used to anesthetize all animals. Blood was collected from the abdominal veins of each animal in each group. Serum was collected by blood centrifugation $\left(2,774 \mathrm{x} \mathrm{g}, 15 \mathrm{~min}, 4^{\circ} \mathrm{C}\right)$ and was preserved at $-80^{\circ} \mathrm{C}$ until analysis. The levels of blood urea nitrogen (BUN) and creatinine in the serum were determined according to methods outlined by the International Federation of Clinical Chemistry (28) using an automated chemical analyzer Hitachi 2070 (Hitachi, Ltd.). All assays were conducted in triplicate using fresh serum. 

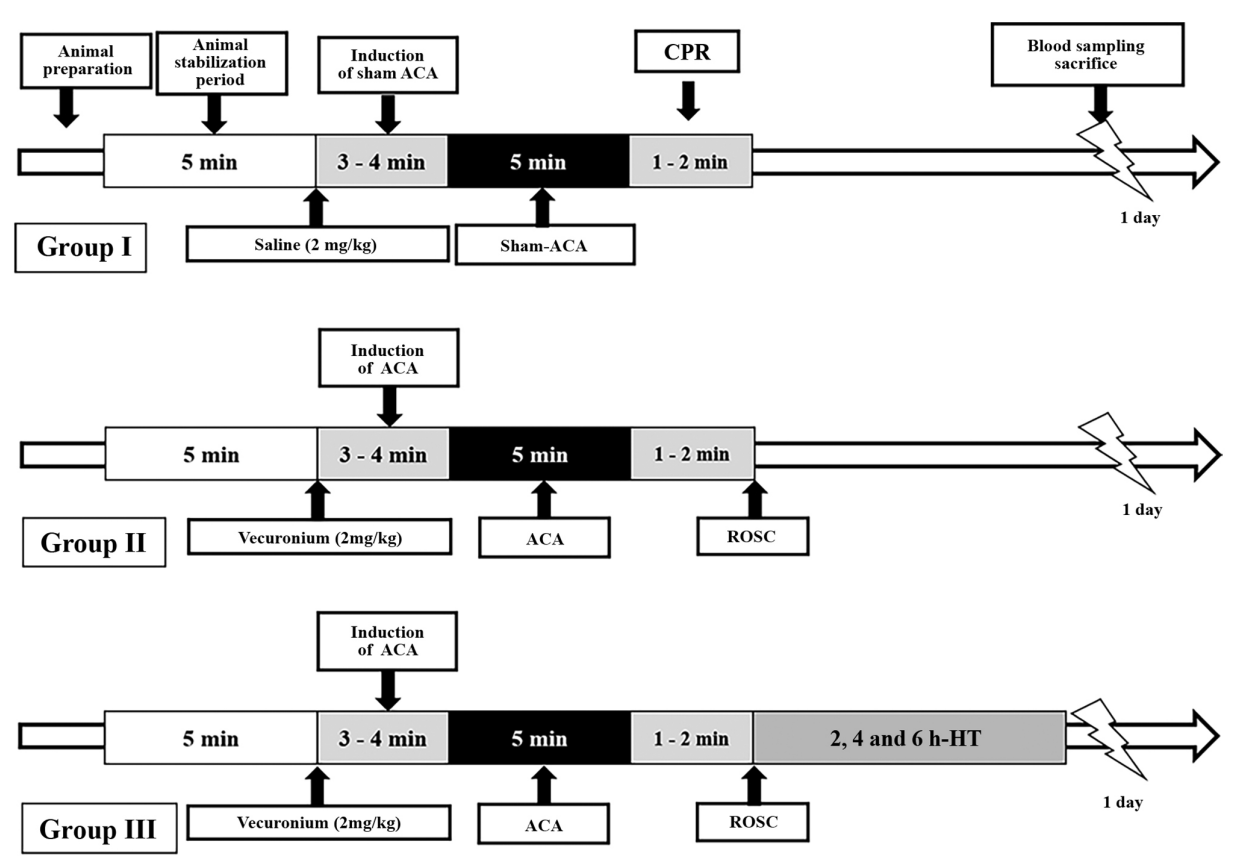

Figure 1. Experimental procedure showing animal stabilization, induction of ACA, CPR and ROSC, HT, blood sampling and sacrifice. HT, hypothermia treatment; ACA, asphyxial cardiac arrest; CPR, cardiopulmonary resuscitation; ROSC, return of spontaneous circulation.

Tissue processing. The rats were deeply anesthetized by an intraperitoneal injection of $200 \mathrm{mg} / \mathrm{kg}$ pentobarbital sodium (JW Pharm Co., Ltd.), and they were perfused transcardially with $0.1 \mathrm{M}$ of phosphate-buffered saline (PBS; pH 7.4), followed by $4 \%$ paraformaldehyde in $0.1 \mathrm{M}$ of phosphate buffer (PB; pH 7.4). Kidneys were isolated from each animal and fixed with $4 \%$ paraformaldehyde in $0.1 \mathrm{M} \mathrm{PB}(\mathrm{pH} 7.4)$ at room temperature during the 1 week, then sliced sagittally, embedded in paraffin and sectioned $(6 \mu \mathrm{m})$.

Hematoxylin and eosin (H\&E), Periodic Acid-Schiff (PAS) and Masson's trichrome staining. H\&E staining was performed to examine pathological changes in the kidneys according to a previously described procedure (29). PAS staining was performed to examine changes in glomeruli according to previously described procedures (30-32). Masson's trichrome staining method was used for defining tubular injury, considering tubular dilatation, tubular atrophy, tubular cast formation, vacuolization, degeneration, interstitial fibrosis and sloughing of tubular epithelial cells, or thickening of the tubular basement membrane according to previously described procedures $(33,34)$.

A total of 2 experienced pathologists evaluated histopathological changes in a double-blinded manner. Images of 10 stained sections/rat were captured at X400 magnifications using a Leica DM 2500 light microscope (Leica Microsystems $\mathrm{GmbH}$ ). A total of 10 fields were analyzed in each section. Histopathological analysis of renal lesions was performed according to previously described procedures $(35,36)$. Briefly, lesions were categorized as no significant microscopic lesions (NSML), minimal, mild, moderate, or marked lesions, respectively, graded using the following scale with the blind test: normal, 0 points; $<25 \%$ damage, 1 point; $26-50 \%$ damage, 2 points; $51-75 \%$ damage, 3 points; and $76-100 \%$ damage, 4 points. Glomerular lesions were defined by loss of cellular elements, collapse of capillary lumen, amorphous hyaline material with or without adhesions to the Bowman's capsule (30-32) and scored by the following numeric scales: no damage, 0 points; very mild, 1 point; mild, 2 points; moderate, 3 points; and severe, 4 points. Tubular injury was scored by the following scoring system: no tubular injury, 0 points; $1-9 \%$ of tubules injured, 1 point; $10-25 \%$ of tubules injured, 2 points; $26-50 \%$ of tubules injured, 3 points; $51-75 \%$ of tubules injured, 4 points; and at least $76 \%$ of tubules injured, 5 points $(33,34)$.

Malondialdehyde (MDA). MDA concentration in the renal cortex was evaluated according to a previously described protocol $(23,37,38)$. In short, the homogenization and centrifugation of the renal tissues were performed at $8,832 \mathrm{x} \mathrm{g}$ for $10 \mathrm{~min}$ at $4^{\circ} \mathrm{C}$, and the supernatant was collected and stored at $-80^{\circ} \mathrm{C}$ for MDA analysis. MDA content was determined according to the instructions of TBARS assay kit (cat. no. 10009055; Cayman Chemical Company).

Immunohistochemistry (IHC) for antioxidant enzymes. IHC was performed with SOD-1, SOD-2, CAT and GPX to study changes in antioxidant immunoreactivities in the kidney. IHC was carried out according to our previously described method (22). In brief, the sections $(6 \mu \mathrm{m})$ were incubated with primary goat anti-SOD1 (1:500; cat. no. SAB2500976; Sigma-Aldrich; Merck KGaA), goat anti-SOD2 (1:1,000; cat. no. SAB2501676; Sigma-Aldrich; Merck KGaA), rabbit anti-CAT (1:1,000; cat. no. ab16731; Abcam) and rabbit anti-GPX (1:1,000; cat. no. ab22604; Abcam) overnight at $4^{\circ} \mathrm{C}$, followed by the biotinylated-conjugated anti-rabbit (1:250; cat. no. BA-1000-1.5; Vector Laboratories, Inc.) and the biotinylated-conjugated anti-goat (1:250; cat. no. BA-5000-1.5; Vector Laboratories, Inc.) secondary antibodies for $2 \mathrm{~h}$ at $24^{\circ} \mathrm{C}$ and developed using Vectastain ABC (Vector Laboratories, Inc.). 
Table I. Physiological condition, asphyxia time and CPR time in Groups I, II and III before CA.

\begin{tabular}{lccccc}
\hline & & & \multicolumn{3}{c}{ Group III } \\
\cline { 4 - 6 } Parameters & Group I & Group II & 2 h-HT & 4 h-HT & 6 h-HT \\
\hline Body weight, g & $355.44 \pm 17.33$ & $354.13 \pm 17.04$ & $284.14 \pm 9.89$ & $278.14 \pm 19.41$ & $283.71 \pm 12.08$ \\
Heart rate, beats/min & $335.14 \pm 8.51$ & $336.34 \pm 6.51$ & $339.78 \pm 16.13$ & $333.50 \pm 9.65$ & $338.67 \pm 9.55$ \\
Room temperature, ${ }^{\circ} \mathrm{C}$ & $36.60 \pm 0.53$ & $23.90 \pm 0.87$ & $25.07 \pm 0.53$ & $25.06 \pm 0.68$ & $24.83 \pm 0.72$ \\
Asphyxia time to CA, sec & - & $162.12 \pm 16.36$ & $145.44 \pm 28.79$ & $148.89 \pm 19.65$ & $150.56 \pm 24.55$ \\
CPR time, sec & - & $71.12 \pm 12.49$ & $72.03 \pm 7.97$ & $69.78 \pm 10.57$ & $73.89 \pm 9.93$ \\
\hline
\end{tabular}

CPR, cardiopulmonary resuscitation; CA, cardiac arrest, HT, hypothermia treatment.

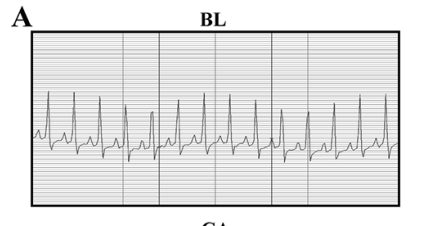

CA
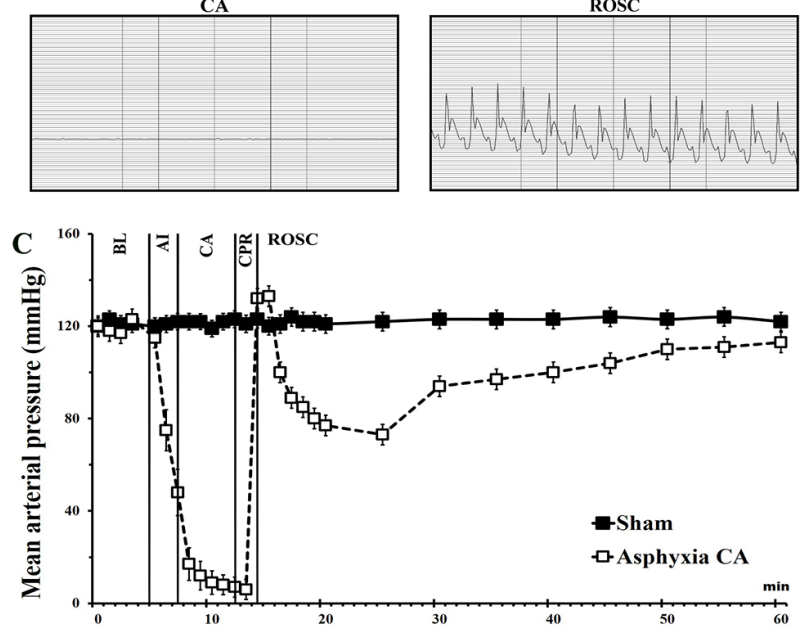

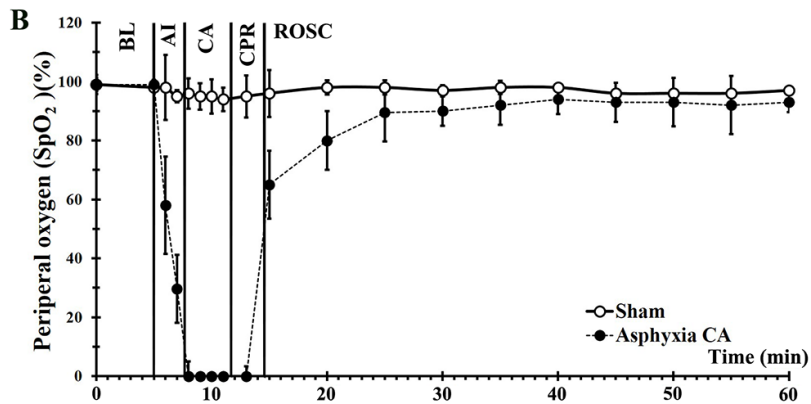

D

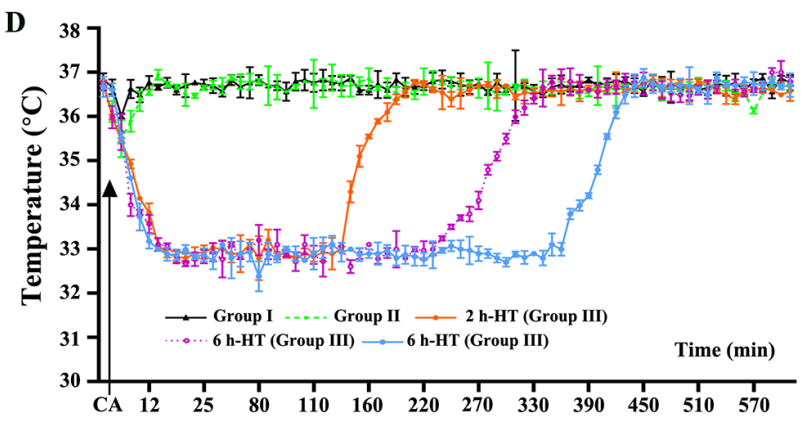

Figure 2. Physiological variables in Groups I, II and III. (A) Electrocardiogram from a representative animal at BL, AI, CA and ROSC. Pulseless electrical activity is shown during CA, although it is often visible during CA. (B) $\mathrm{SpO}_{2}$ levels were revealed during CA, CPR and ROSC. (C) Mean arterial pressure is shown during CA, CPR and ROSC. (D) Temperature management following ROSC. Data are expressed as the means \pm SEM. HT, hypothermia treatment; CA, cardiac arrest; ROSC, return of spontaneous circulation; CPR, cardiopulmonary resuscitation; BL, baseline; AI, asphyxia induction.

Then, they were visualized with 3,3'-diaminobenzidine solution (in 0.1 M Tris-HCl buffer).

Leica DM 2500 microscope was used to image the sections at a magnification of $\mathrm{x} 400$. A total of 10 sections/rat were selected and 10 areas were captured. Image J threshold analysis software version 1.52a (National Institutes of Health) was used to measure the percent (\%) of relative optical density (ROD).

Statistical analysis. All experiments were repeated in triplicate. Graph Pad Prism version 5.0 (GraphPad Software, Inc.) was used to analyze the data, which were expressed as the means \pm standard error of the mean (SEM) values. Survival was analyzed using Kaplan-Meier statistics and the log-rank test. MAP and peripheral oxygen were compared using one- and two-way repeated-measures of analysis of variance to assess the effect of time. To determine the significance of differences, post hoc analyses were conducted using Tukey's test for all pairwise multiple comparisons. $\mathrm{P}<0.05$ was considered to indicate a statistically significant difference.

\section{Results}

Physiological changes, the survival rate and serum biochemical variables. There was no statistically significant difference among the groups regarding baseline characteristics, including body weight, MAP and $\mathrm{SpO}_{2}$ (Table I and Fig. 2). The induction of CA occurred 3-4 min following the intravenous injection of vecuronium bromide $(2 \mathrm{mg} / \mathrm{kg})$. CA was confirmed with an isoelectric ECG, $\mathrm{SpO}_{2}$ and MAP, and these changed as expected according to the experimental protocol (Fig. 2A-C). As revealed in Fig. 2D, the body temperature was different among all groups following ROSC.

As revealed in Fig. 3, the survival rate of each group was evaluated at one day post-CA. The rate of Group II was $42.9 \%$. 


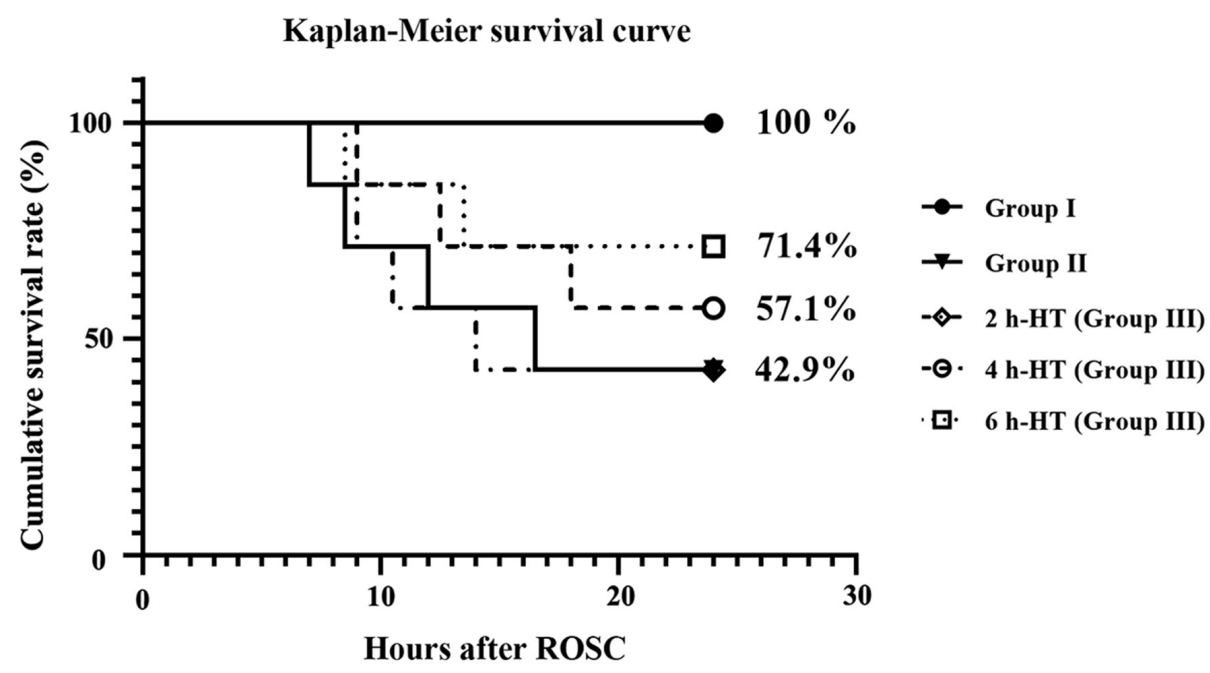

Figure 3. Cumulative survival rate using Kaplan-Meier analysis in Groups I, II and III by time point after ROSC. Group III had different survival rates from those revealed in Group II (log-rank test, $\mathrm{P}<0.05$ ). ROSC, return of spontaneous circulation; HT, hypothermia treatment.
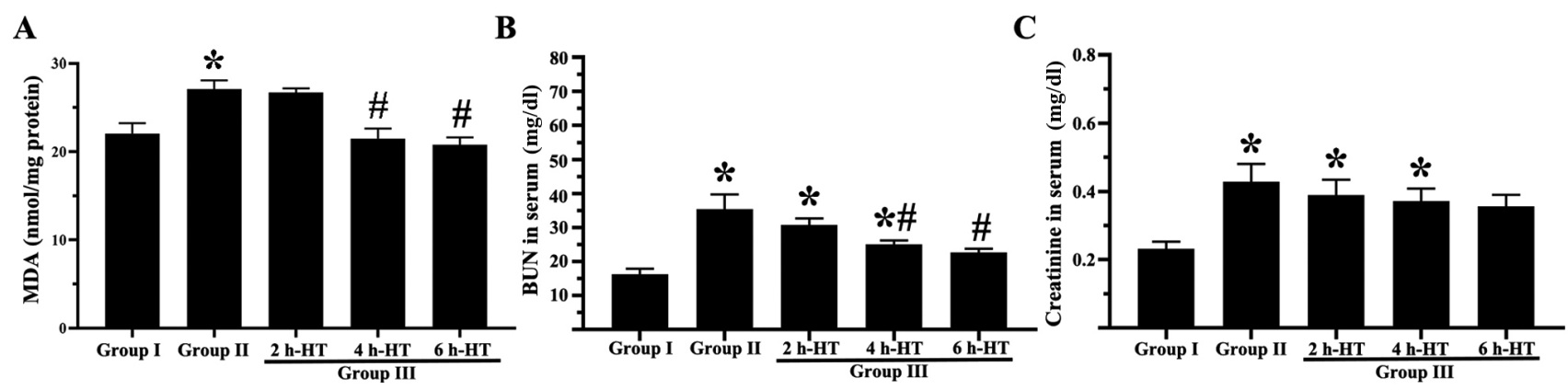

Figure 4. MDA, serum BUN and creatinine levels of the renal cortex tissue. (A) MDA levels. The levels were significantly increased in Group II 1 day following cardiac arrest; however, the levels in Group III were significantly decreased following $4 \mathrm{~h}$ - and $6 \mathrm{~h}-\mathrm{HT}$ when compared with Group II. Serum (B) BUN and (C) creatinine levels. The levels were significantly increased in Group II; however, the levels in Group III were decreased following $6 \mathrm{~h}-\mathrm{HT}$ when compared with Group II. "P<0.05 vs. Group I; ${ }^{\#} \mathrm{P}<0.05$ vs. Group II. MDA, malondialdehyde; HT, hypothermia treatment; BUN, blood urea nitrogen.

In group III, the rate following $2 \mathrm{~h}-\mathrm{HT}$ was $42.9 \%$, the rate following $4 \mathrm{~h}-\mathrm{HT}$ was $57.1 \%$ and the rate following $6 \mathrm{~h}-\mathrm{HT}$ was $71.4 \%$. In this experiment, there was no difference between the rats in Group II and the rats with $2 \mathrm{~h}-\mathrm{HT}$ in Group III.

As demonstrated in Fig. 4B, the serum BUN level in Group I was $13.8 \mathrm{mg} / \mathrm{dl}$ one day post-CA. In group II, the BUN level was significantly increased to $35.3 \mathrm{mg} / \mathrm{dl}$. In Group III, the BUN level was $30.7 \mathrm{mg} / \mathrm{dl}$ following $2 \mathrm{~h}-\mathrm{HT}$, $25.0 \mathrm{mg} / \mathrm{dl}$ following $4 \mathrm{~h}-\mathrm{HT}$ and $22.7 \mathrm{mg} / \mathrm{dl}$ following $6 \mathrm{~h}-\mathrm{HT}$. In addition, as revealed in Fig. $4 \mathrm{C}$, the serum creatinine level in Group I was $0.23 \mathrm{mg} / \mathrm{dl}$. In group II, the creatinine level was significantly increased to $0.43 \mathrm{mg} / \mathrm{dl}$. In group III, the creatinine levels were lower than that observed in Group II as follows: $0.39 \mathrm{mg} / \mathrm{dl}$ following $2 \mathrm{~h}-\mathrm{HT}, 0.37 \mathrm{mg} / \mathrm{dl}$ following $4 \mathrm{~h}-\mathrm{HT}$ and $0.36 \mathrm{mg} / \mathrm{dl}$ following $6 \mathrm{~h}-\mathrm{HT}$.

Histopathological findings. In Group I (sham), intact histological structures were revealed by H\&E, PAS and Masson's trichrome staining (Fig. 5A). The interstitial fibrosis was not detected in all groups, meanwhile in Group II, CA-induced renal histopathology was examined at one day following ROSC using H\&E, PAS and Masson's trichrome staining. Severe CA-induced kidney injury was significantly increased in the proximal tubules and glomeruli; particularly, the brush borders of the renal tubular epithelial cells were seriously eroded (Fig. 5A and B). In addition, in this group, glomerular capillaries were dilated with inflammatory cells, and interstitial edema and acute renal tubular necrosis were serious as compared with those observed in Group I (Fig. 5A).

In Group III, kidney injury was attenuated at one day following ROSC (Fig. 5A and B). In particular, CA-induced injury in the proximal tubules was significantly decreased following $6 \mathrm{~h}-\mathrm{HT}$ as compared with that observed in Group II. In addition, local expansion of the proximal tubules was decreased as compared with that revealed in Group II (Fig. 5A). For the glomeruli, 6 h-HT significantly attenuated glomerular injury as compared with that revealed in Group II (Fig. 5A and B).

MDA level. As revealed in Fig. 4A, the level of MDA in the renal cortex was significantly increased at one day following CA in Group II compared with Group I. However, in Group III, the level of MDA was significantly decreased following $4 \mathrm{~h}$ - and $6 \mathrm{~h}$-HT. It was also decreased in the $2 \mathrm{~h}-\mathrm{HT}$, but there was no statistically significant difference compared with Group II. 
A

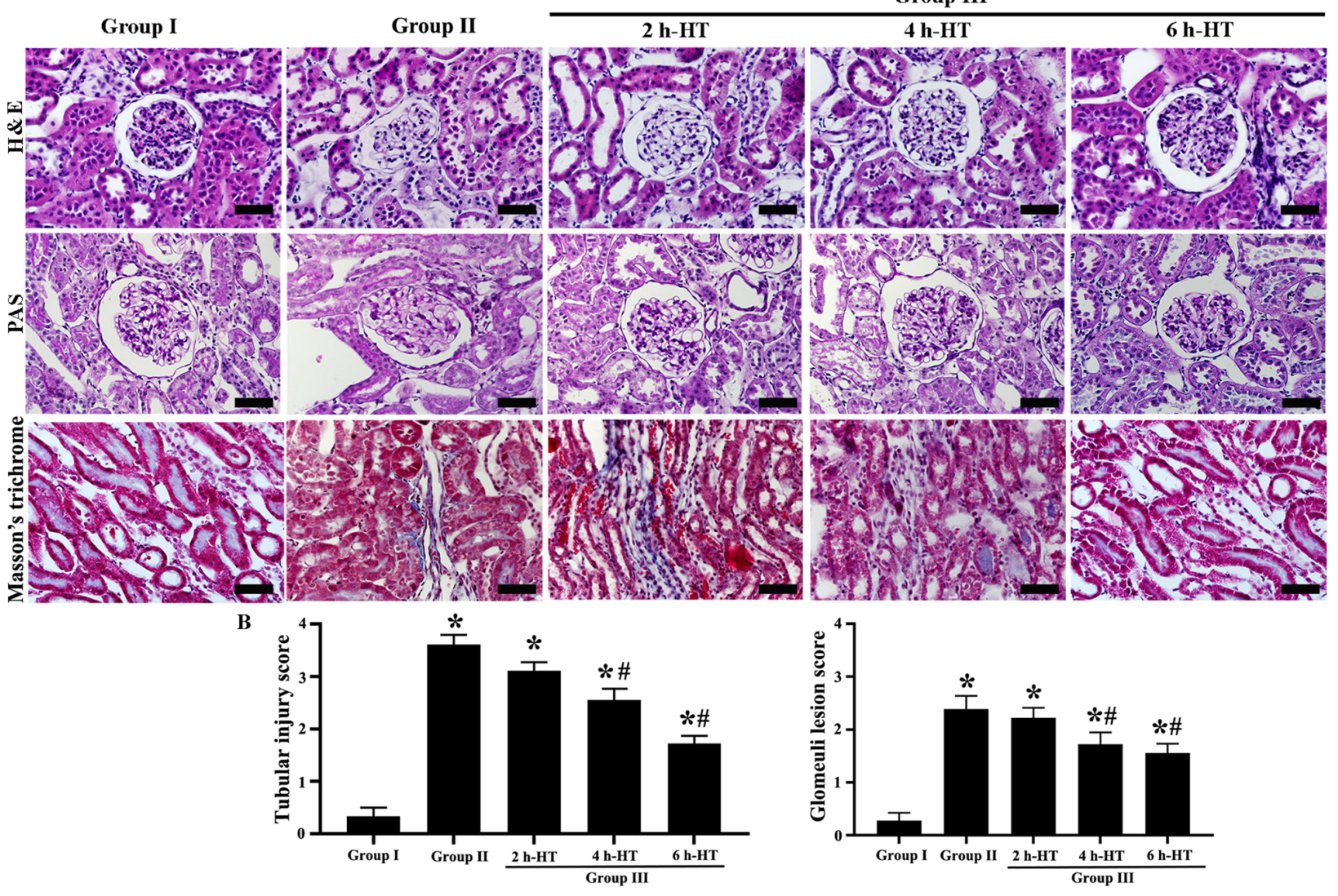

Figure 5. Histology of renal tissues in each group. (A) Histopathological findings of the kidneys of Groups I, II and III with 2 h-, 4 h- and 6 h-HT following CA. CA-induced renal injury was attenuated in Group III with $6 \mathrm{~h}$-HT. Original magnification, $\mathrm{x} 400$. Scale bar, $50 \mu \mathrm{m}$. (B) Histograms of tubular injury score and glomerular lesion score. The scores in Group III with 6 h-HT were significantly decreased when compared with Group II. " $\mathrm{P}<0.05$ vs. Group I; " $\mathrm{P}<0.05$ vs. Group II. HT, hypothermia treatment; CA, cardiac arrest; H\&E, hematoxylin and eosin; PAS, periodic acid-Schiff.

Findings of antioxidant enzyme immunoreactivities. In Group I, normal SOD-1, SOD-2, GPX and CAT immunoreactivities were evaluated, revealing that they were principally located in the tubules (Fig. 6A). In Group II, SOD-1, SOD-2, GPX and CAT immunoreactivities were significantly reduced at one day following ROSC as compared with those revealed in Group I (Fig. 6A and B).

In Group III, SOD-1, SOD-2, GPX and CAT immunoreactivities following $2 \mathrm{~h}$-HT were not significantly different from those observed in Group II (Fig. 6A and B). In the case of $4 \mathrm{~h}-\mathrm{HT}$, the four immunoreactivities were significantly higher than those revealed in Group II (Fig. 6A and B), demonstrating that, in particular, GPX immunoreactivity was significantly higher compared with the other immunoreactivities. In the case of $6 \mathrm{~h}-\mathrm{HT}$, all immunoreactivities were higher than those identified in the rats which received $4 \mathrm{~h}-\mathrm{HT}$, revealing that the ROD of each SOD-1, SOD-2, GPX and CAT immunoreactivity was $78.4,67.4,86.5$ and $79.5 \%$, respectively, as compared with Group I (Fig. 6A and B).

\section{Discussion}

In animal studies, the heart and brain are the most affected organs following ischemia/reperfusion (I/R) injury after CA $(39,40)$. Nevertheless, certain studies have reported that acute kidney injury has an impact on neurological recovery $(41,42)$. Therefore, it is important to investigate acute kidney injury following CA and CPR. In the present study, adult male SD rats were used for asphyxial CA by injecting vecuronium bromide. CA was confirmed 3-4 min following induction of asphyxia and CPR was performed $5 \mathrm{~min}$ after CA. MAP, ECG and $\mathrm{SpO}_{2}$ were altered as expected during $\mathrm{CA}$ and following ROSC. In our present study, the survival rate in Group III was $42.9 \%$ one day following ROSC in rats exposed to $2 \mathrm{~h}-\mathrm{HT}, 57.1 \%$ in rats treated with $4 \mathrm{~h}-\mathrm{HT}$, and $71.4 \%$ in rats subjected to 6 h-HT. Che et al (26) reported that the survival rate was $40 \%$ two days following ROSC in a rat model of asphyxial CA. In addition, Wang et al (43) reported that in rats, the combination of hypothermia and levosimendan (a calcium sensitizer and potassium-channel opener) following ROSC significantly increased survival. Based on these findings, HT in rats with $\mathrm{CA}$ may increase the survival rate a few days following ROSC. However, in humans, HT after CA hardly increased the survival rate following ROSC (44).

Renal dysfunction was reported in $12-28 \%$ of patients with CA following successful resuscitation (13). In addition, acute kidney injury developed in $43 \%$ of patients resuscitated after $\mathrm{CA}$, and more than $75 \%$ of these episodes occurred within three days following CA (45). In animal models, acute kidney injury induced by I/R (i.e., ROSC following CA) was significantly attenuated by HT $(43,46,47)$. For example, Tissier et al (47) reported significant attenuation of kidney lesions by HT in 
A
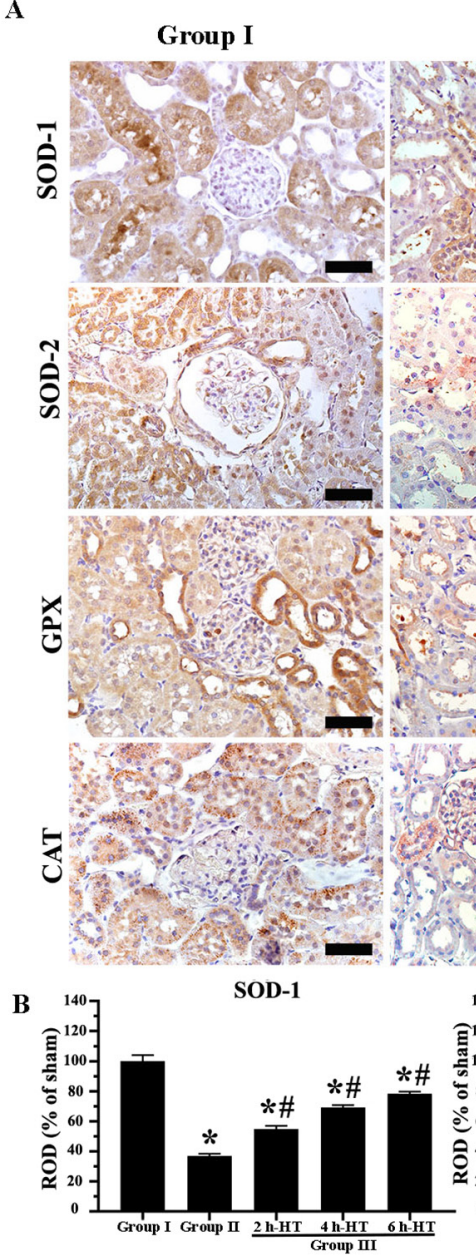

Group II

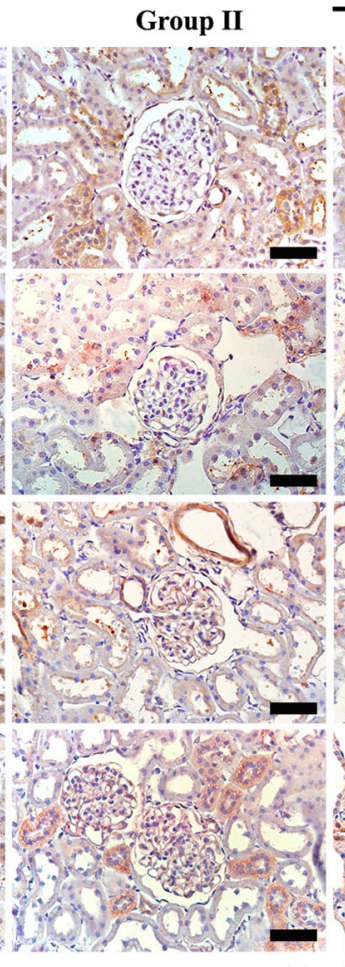

SOD-2

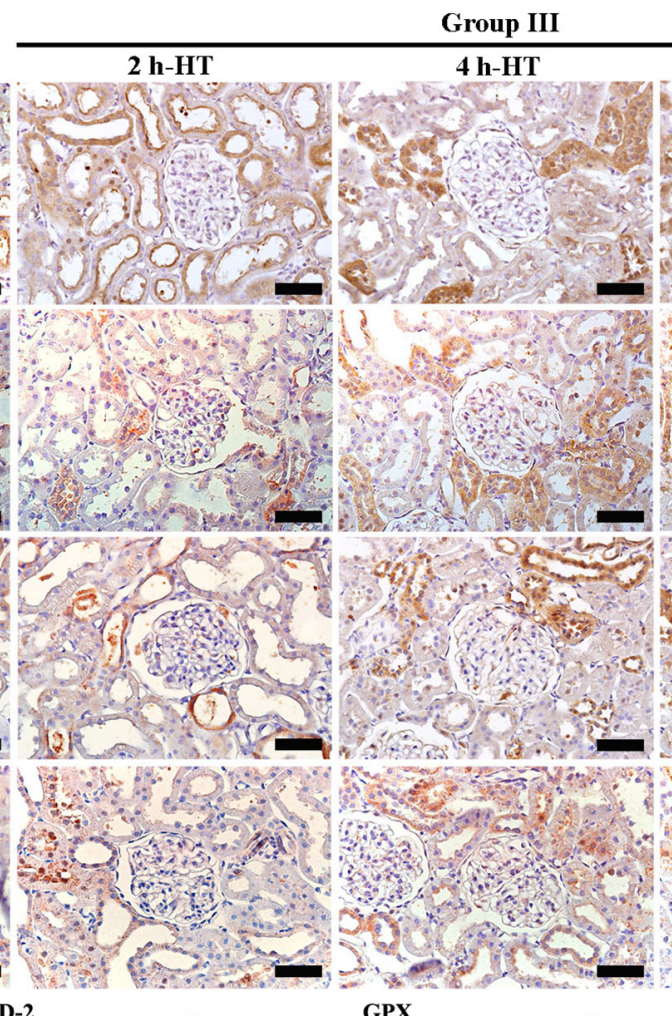

GPX

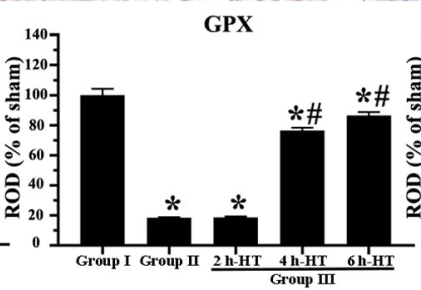

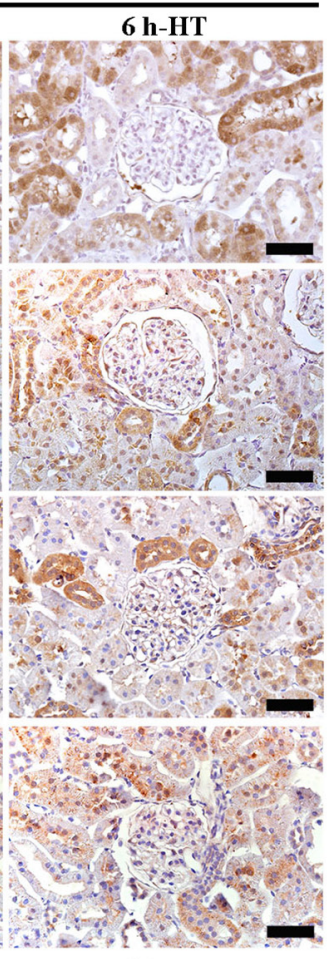

CAT

Figure 6. Immunohistochemistry analysis of antioxidant enzyme expression in renal cortex tissue. (A) Immunoreactivities of antioxidant enzymes (SOD-1, SOD-2, GPX and CAT) in the kidneys of Groups I, II and III were altered. All immunoreactivities in Group III with 6 h-HT were markedly increased when compared with Group II. Original magnification, x400. Scale bar, $50 \mu \mathrm{m}$. (B) ROD of SOD-1, SOD-2, GPX and CAT immunoreactivities. The ROD in Group III with 6 h-HT was significantly increased when compared with Group II. ${ }^{*} \mathrm{P}<0.05$ vs. Group I; ${ }^{*} \mathrm{P}<0.05$ vs. Group II. SOD, superoxide dismutase; GPX, glutathione peroxidase; CAT, catalase; ROD, relative optical density; HT, hypothermia treatment.

a rabbit model of CA, based on histopathology and electron microscopy, compared with the control group. In our present study, the histopathological glomerular and tubular lesion scores of kidneys in Group II were apparently enhanced one day following ROSC. In this group, serum BUN and creatinine levels were significantly increased following ROSC when compared with the sham group (Group I). These results were similar to those of previous studies involving canine, rabbit and piglet CA models (47-49). Thus, kidney injury was severely increased in the early phase following CA in experimental animals. In our present study, renal glomerular and tubular lesions and histopathological scores in Group III were significantly reduced following $4 \mathrm{~h}$ - and $6 \mathrm{~h}-\mathrm{HT}$ one day following ROSC compared with Group II. Ribeiro et al (46) and Souza et al (50) reported that HT was effective in animal models of renal I/R injury. Islam et al (23) and Jawad et al (22) determined that HT reduced the severity of renal injury and increased the survival rate in an asphyxial CA model. The findings suggested that HT has a significant renal-protective effect, which was associated with an increased survival rate.

Endogenous antioxidant enzymes mainly include SODs, CAT and GPX. These enzymes provide a first line of defense against $\mathrm{O}_{2}{ }^{-\bullet}$ and $\mathrm{OH} \bullet$. SOD-1 and SOD-2 provide a defense against oxidative stress by catalyzing the dismutation of $\mathrm{O}_{2}{ }^{-}$ into $\mathrm{O}_{2}$ and $\mathrm{H}_{2} \mathrm{O}_{2}$ (51). Oxidative stress is a crucial factor in organ injury and hemodynamic dysfunction during PCAS and the generation of ROS during I/R injury. The activity of antioxidant enzymes is altered by I/R injury following CA (21). Our study revealed that SOD-1, SOD-2, GPX and CAT levels were decreased following ROSC in Group II compared with Group I. The levels of these antioxidant enzymes are reduced following I/R, which causes cell damage and death due to the consumption of endogenous antioxidants as a result of ROS release (52).

Xia et al (53) reported increased antioxidant activity in kidney tissues of mice exposed to HT in renal I/R injury. Hackenhaar et al (21) observed a significant increase in the activity of SOD-1, SOD-2, GPX and CAT after 6, 12, 36 and 72-h HT in humans following ROSC. In previous studies using a rat model of asphyxial CA, Islam et al (23) reported that HT following CA reduced oxidative stress in the kidney and Jawad et al (22) reported that HT following CA protected the kidney against injury induced by $\mathrm{CA}$, demonstrating that Nrf2/HO-1 was increased in the kidney. In our present study, 
the immunoreactivities of SOD-1, SOD-2, GPX and CAT were significantly increased following $4 \mathrm{~h}-\mathrm{HT}$ and $6 \mathrm{~h}-\mathrm{HT}$ in Group III when compared with Group II, suggesting that HT activated antioxidant enzymes and reduced the oxidative stress.

Based on the survival, histopathology, biochemical and immunohistochemical results of this study, it was determined that renal dysfunction is common and associated with mortality in the early stages of PCAS following ROSC, in our rat model of asphyxial CA. However, $4 \mathrm{~h}$ - or 6 h-HT following ROSC significantly reduced renal injury, suggesting that HT induces activation of antioxidant enzymes, such as SOD-1, SOD-2, GPX and CAT, resulting in reduced oxidative stress in the kidneys. As a result, it was hypothesized that HT reduces renal injury by an antioxidant mechanism and increases the early survival rate. However, western blot analysis is required to elucidate the mechanism of renal injury and HT in CA following ROSC. This is a potential limitation of the present study and underscores the need for further studies.

\section{Acknowledgements}

Not applicable.

\section{Funding}

The present study was supported by the Basic Science Research Program through the National Research Foundation of Korea funded by the Ministry of Education (grant nos. NRF-2019R1C1C1002564, NRF-2019R1F1A1062696 and NRF-2021R1F1A1059992).

\section{Availability of data and materials}

The datasets used and/or analyzed during the current study are available from the corresponding author on reasonable request.

\section{Authors' contributions}

SEK, HYS, MHW and HJT were responsible for the experimental design, data acquisition, data analysis and manuscript writing. EYL, YJY, RHK, JHC and TKL performed the experiments and data analysis. DCA, BYP, JCY, SKH and ISK performed the data analysis and made critical comments on the entire process of the study. All authors have read and approved the final manuscript. HYS and HJT confirm the authenticity of all the raw data.

\section{Ethics approval and consent to participate}

All experimental protocols were approved based on ethical procedures and scientific care by the Institutional Animal Care and Use Committee of Jeonbuk National University (approval no. JBNU 2020-084; Jeonju, South Korea).

\section{Patient consent for publication}

Not applicable.

\section{Competing interests}

The authors declare that they have no competing interests.

\section{References}

1. Girotra S, Chan PS and Bradley SM: Post-resuscitation care following out-of-hospital and in-hospital cardiac arrest. Heart 101: 1943-1949, 2015.

2. Roh YI, Jung WJ, Hwang SO, Kim S, Kim HS, Kim JH, Kim TY, Kang HS, Lee JS and Cha KC: Shorter defibrillation interval promotes successful defibrillation and resuscitation outcomes. Resuscitation 143: 100-105, 2019.

3. Xanthos T, Iacovidou N, Pantazopoulos I, Vlachos I, Bassiakou E, Stroumpoulis K, Kouskouni E, Karabinis A and Papadimitriou L: Ischaemia-modified albumin predicts the outcome of cardiopulmonary resuscitation: An experimental study. Resuscitation 81: 591-595, 2010.

4. Yeh ST, Cawley RJ, Aune SE and Angelos MG: Oxygen requirement during cardiopulmonary resuscitation (CPR) to effect return of spontaneous circulation. Resuscitation 80: 951-955, 2009.

5. López-Herce J, del Castillo J, Matamoros M, Canadas S, Rodriguez-Calvo A, Cecchetti C, Rodríguez-Núnez A and Carrillo Á; Iberoamerican Pediatric Cardiac Arrest Study Network RIBEPCI: Post return of spontaneous circulation factors associated with mortality in pediatric in-hospital cardiac arrest: A prospective multicenter multinational observational study. Crit Care 18: 607, 2014.

6. Mongardon N, Dumas F, Ricome S, Grimaldi D, Hissem T, Pène F and Cariou A: Postcardiac arrest syndrome: From immediate resuscitation to long-term outcome. Ann Intensive Care 1: 45, 2011.

7. Neumar RW, Nolan JP, Adrie C, Aibiki M, Berg RA, Böttiger BW, Callaway C, Clark RS, Geocadin RG, Jauch EC, et al: Post-cardiac arrest syndrome: Epidemiology, pathophysiology, treatment, and prognostication. A consensus statement from the International Liaison Committee on Resuscitation (American Heart Association, Australian and New Zealand Council on Resuscitation, European Resuscitation Council, Heart and Stroke Foundation of Canada, InterAmerican Heart Foundation, Resuscitation Council of Asia, and the Resuscitation Council of Southern Africa); the American Heart Association Emergency Cardiovascular Care Committee; the Council on Cardiovascular Surgery and Anesthesia; the Council on Cardiopulmonary, Perioperative, and Critical Care; the Council on Clinical Cardiology; and the Stroke Council. Circulation 118: 2452-2483, 2008.

8. Nolan JP, Neumar RW, Adrie C, Aibiki M, Berg RA, Böttiger BW, Callaway C, Clark RS, Geocadin RG, et al: Post-cardiac arrest syndrome: epidemiology, pathophysiology, treatment, and prognostication. A Scientific Statement from the International Liaison Committee on Resuscitation; the American Heart Association Emergency Cardiovascular Care Committee; the Council on Cardiovascular Surgery and Anesthesia; the Council on Cardiopulmonary, Perioperative, and Critical Care; the Council on Clinical Cardiology; the Council on Stroke. Resuscitation 79: 350-79, 2008. doi: 10.1016/j.resuscitation.2008.09.017

9. Jentzer JC, Chonde MD and Dezfulian C: Myocardial Dysfunction and shock after cardiac arrest. BioMed Res Int 2015: 314796, 2015.

10. Madl C and Holzer M: Brain function after resuscitation from cardiac arrest. Curr Opin Crit Care 10: 213-217, 2004.

11. Roberts BW, Kilgannon JH, Chansky ME, Mittal N, Wooden J, Parrillo JE and Trzeciak S: Multiple organ dysfunction after return of spontaneous circulation in postcardiac arrest syndrome. Crit Care Med 41: 1492-1501, 2013.

12. Zeiner A, Sunder-Plassmann G, Sterz F, Holzer M, Losert H, Laggner AN and Müllner M: The effect of mild therapeutic hypothermia on renal function after cardiopulmonary resuscitation in men. Resuscitation 60: 253-261, 2004.

13. Yanta J, Guyette FX, Doshi AA, Callaway CW and Rittenberger JC; Post Cardiac Arrest Service: Renal dysfunction is common following resuscitation from out-of-hospital cardiac arrest. Resuscitation 84: 1371-1374, 2013.

14. Lee JH, Lee TK, Kim IH, Lee JC, Won MH, Park JH, Ahn JH, Shin MC, Ohk TG, Moon JB, et al: Changes in histopathology and tumor necrosis factor- $\alpha$ levels in the hearts of rats following asphyxial cardiac arrest. Clin Exp Emerg Med 4: 160-167, 2017. 
15. Uchino S, Kellum JA, Bellomo R, Doig GS, Morimatsu H, Morgera S, Schetz M, Tan I, Bouman C, Macedo E, et al; Beginning and Ending Supportive Therapy for the Kidney (BEST Kidney) Investigators: Acute renal failure in critically ill patients: A multinational, multicenter study. JAMA 294: 813-818, 2005.

16. Mattana J and Singhal PC: Prevalence and determinants of acute renal failure following cardiopulmonary resuscitation. Arch Intern Med 153: 235-239, 1993.

17. Sachse A and Wolf G: Angiotensin II-induced reactive oxygen species and the kidney. J Am Soc Nephrol 18: 2439-2446, 2007.

18. Baud L and Ardaillou R: Reactive oxygen species: Production and role in the kidney. Am J Physiol 251: F765-F776, 1986.

19. Rodrigo R, Fernández-Gajardo R, Gutiérrez R, Matamala JM, Carrasco R, Miranda-Merchak A and Feuerhake W: Oxidative stress and pathophysiology of ischemic stroke: Novel therapeutic opportunities. CNS Neurol Disord Drug Targets 12: 698-714, 2013.

20. Shahzad S, Hasan A, Faizy AF, Mateen S, Fatima N and Moin S: Elevated DNA damage, oxidative stress, and impaired response defense system inflicted in patients with myocardial infarction. Clin Appl Thromb Hemost 24: 780-789, 2018.

21. Hackenhaar FS, Medeiros TM, Heemann FM, Behling CS, Putti JS, Mahl CD, Verona C, da Silva ACA, Guerra MC, Gonçalves CAS, et al: Therapeutic hypothermia reduces oxidative damage and alters antioxidant defenses after cardiac arrest. Oxid Med Cell Longev 2017: 8704352, 2017.

22. Jawad A, Yoo YJ, Cho JH, Yoon JC, Tian W, Islam MS, Lee EY, Shin HY, Kim SE, Kim K, et al: Therapeutic hypothermia effect on asphyxial cardiac arrest-induced renal ischemia/reperfusion injury via change of Nrf2/HO-1 levels. Exp Ther Med 22: 1031, 2021.

23. Islam A, Kim SE, Yoon JC, Jawad A, Tian W, Yoo YJ, Kim IS, Ahn D, Park BY, Hwang Y, et al: Protective effects of therapeutic hypothermia on renal injury in an asphyxial cardiac arrest rat model. J Therm Biol 94: 102761, 2020.

24. Drabek T, Janata A, Wilson CD, Stezoski J, Janesko-Feldman K, Tisherman SA, Foley LM, Verrier JD and Kochanek PM: Minocycline attenuates brain tissue levels of TNF- $\alpha$ produced by neurons after prolonged hypothermic cardiac arrest in rats. Resuscitation 85: 284-291, 2014.

25. Han F, Boller M, Guo W, Merchant RM, Lampe JW, Smith TM and Becker LB: A rodent model of emergency cardiopulmonary bypass resuscitation with different temperatures after asphyxial cardiac arrest. Resuscitation 81: 93-99, 2010.

26. Che D, Li L, Kopil CM, Liu Z, Guo W and Neumar RW: Impact of therapeutic hypothermia onset and duration on survival, neurologic function, and neurodegeneration after cardiac arrest. Crit Care Med 39: 1423-1430, 2011.

27. Park Y, Ahn JH, Cho JH, Tae HJ, Lee TK, Kim B, Lee JC, Park JH, Shin MC, Ohk TG, et al: Effects of hypothermia on inflammatory cytokine expression in rat liver following asphyxial cardiac arrest. Exp Ther Med 21: 626, 2021.

28. Varming K, Forsum U, Bruunshuus I and Olesen H: International Federation of Clinical Chemistry and Laboratory Medicine: Scientific Division. EJIFCC 15: 10-13, 2004

29. Nam SM, Kim JW, Yoo DY, Choi JH, Kim W, Jung HY, Won MH, Hwang IK, Seong JK and Yoon YS: Effects of treadmill exercise on neural stem cells, cell proliferation, and neuroblast differentiation in the subgranular zone of the dentate gyrus in cyclooxygenase-2 knockout mice. Neurochem Res 38: 2559-2569, 2013.

30. Duarte CG, Zhang $J$ and Ellis S: Effects of radiocontrast and endothelin administration on systolic blood pressure and renal damage in male spontaneously hypertensive and Wistar Kyoto rats with phentolamine-induced adrenergic blockade. Invest Radiol 33: 104-112, 1998.

31. Raij L, Azar S and Keane W: Mesangial immune injury, hypertension, and progressive glomerular damage in Dahl rats. Kidney Int 26: 137-143, 1984.

32. Slaughter TN, Paige A, Spires D, Kojima N, Kyle PB, Garrett MR, Roman RJ and Williams JM: Characterization of the development of renal injury in Type-1 diabetic Dahl salt-sensitive rats. Am J Physiol Regul Integr Comp Physiol 305: R727-R734, 2013.

33. Canales BK, Reyes L, Reinhard MK, Khan SR, Goncalves CG and Meguid MM: Renal glomerular and tubular injury after gastric bypass in obese rats. Nutrition 28: 76-80, 2012.
34. Kang DH, Kim YG, Andoh TF, Gordon KL, Suga S, Mazzali M, Jefferson JA, Hughes J, Bennett W, Schreiner GF, et al: Post-cyclosporine-mediated hypertension and nephropathy: Amelioration by vascular endothelial growth factor. Am J Physiol Renal Physiol 280: F727-F736, 2001.

35. Açıkgöz Ş, Edebali N, Barut F, Can M, Tekin İÖ, Büyükuysal Ç and Açıgöz B: Ischemia modified albumin increase indicating cardiac damage after experimental subarachnoid hemorrhage. BMC Neurosci 15: 33, 2014.

36. Klopfleisch R: Multiparametric and semiquantitative scoring systems for the evaluation of mouse model histopathology - a systematic review. BMC Vet Res 9: 123, 2013.

37. Li J, Jiang H, Wu P, Li S, Han B, Yang Q, Wang X, Han B, Deng N, Qu B, et al: Toxicological effects of deltamethrin on quail cerebrum: Weakened antioxidant defense and enhanced apoptosis. Environ Pollut 286: 117319, 2021.

38. Yang D, Yang Q, Fu N, Li S, Han B, Liu Y, Tang Y, Guo X, Lv Z and Zhang Z: Hexavalent chromium induced heart dysfunction via Sesn2-mediated impairment of mitochondrial function and energy supply. Chemosphere 264: 128547, 2021.

39. Nguyen Thi PA, Chen MH, Li N, Zhuo XJ and Xie L: PD98059 protects brain against cells death resulting from ROS/ERK activation in a cardiac arrest rat model. Oxid Med Cell Longev 2016: $3723762,2016$.

40. Yin XL, Shen H, Zhang W and Yang Y: Inhibition of endoplasm reticulum stress by anisodamine protects against myocardial injury after cardiac arrest and resuscitation in rats. Am J Chin Med 39: 853-866, 2011.

41. Chou AH, Lee CM, Chen CY, Liou JT, Liu FC, Chen YL and Day YJ: Hippocampal transcriptional dysregulation after renal ischemia and reperfusion. Brain Res 1582: 197-210, 2014.

42. Schuck PF, Alves L, Pettenuzzo LF, Felisberto F, Rodrigues LB, Freitas BW, Petronilho F, Dal-Pizzol F, Streck EL and Ferreira GC: Acute renal failure potentiates methylmalonate-induced oxidative stress in brain and kidney of rats. Free Radic Res 47: 233-240, 2013.

43. Wang $\mathrm{CH}$, Chang WT, Tsai MS, Huang $\mathrm{CH}$ and Chen WJ: Synergistic effects of moderate therapeutic hypothermia and levosimendan on cardiac function and survival after asphyxia-induced cardiac arrest in rats. J Am Heart Assoc 9: e016139, 2020.

44. Safar PJ and Kochanek PM: Therapeutic hypothermia after cardiac arrest. N Engl J Med 346: 612-613, 2002.

45. Tujjar O, Mineo G, Dell'Anna A, Poyatos-Robles B, Donadello K, Scolletta S, Vincent JL and Taccone FS: Acute kidney injury after cardiac arrest. Crit Care 19: 169, 2015.

46. Ribeiro GB, Santos EBD, Bona SR, Schaefer PG, Garcez TA, Rabolini EB, Smaniotto GP, Marroni NP and Corso CO: The effects of local ischemic preconditioning and topical hypothermia in renal ischemia/reperfusion injury in rats. Acta Cir Bras 32: 816-826, 2017.

47. Tissier R, Giraud S, Quellard N, Fernandez B, Lidouren F, Darbera L, Kohlhauer M, Pons S, Chenoune M, Bruneval P, et al: Kidney protection by hypothermic total liquid ventilation after cardiac arrest in rabbits. Anesthesiology 120: 861-869, 2014.

48. Bleske BE, Song J, Chow MS, Kluger J and White CM: Hematologic and chemical changes observed during and after cardiac arrest in a canine model - a pilot study. Pharmacotherapy 21: 1187-1191, 2001.

49. Hang CC, Li CS, Wu CJ and Yang J: Acute kidney injury after cardiac arrest of ventricular fibrillation and asphyxiation swine model. Am J Emerg Med 32: 208-215, 2014.

50. Souza PC, Santos EBD, Motta GL, Bona SR, Schaefer PG, Campagnol D, Bortolini T and Corso CO: Combined effects of melatonin and topical hypothermia on renal ischemia-reperfusion injury in rats. Acta Cir Bras 33: 197-206, 2018.

51. Tae HJ, Park JH, Cho JH, Kim IH, Ahn JH, Lee JC, Kim JD, Park J, Choi SY and Won MH: Oenanthe javanica extract increases immunoreactivities of antioxidant enzymes in the rat kidney. Chin Med J (Engl) 127: 3758-3763, 2014.

52. Sehitoglu MH, Karaboga I, Kiraz A and Kiraz HA: The hepatoprotective effect of Aloe vera on ischemia-reperfusion injury in rats. North Clin Istanb 6: 203-209, 2018.

53. Xia Z, Wang W, Xiao Q, Ye Q, Zhang X and Wang Y: Mild hypothermia protects renal function in ischemia-reperfusion kidney: an experimental study in mice. Transplant Proc 50: 3816-3821, 2018.

This work is licensed under a Creative Commons

Attribution-NonCommercial-NoDerivatives 4.0

International (CC BY-NC-ND 4.0) License. 